\title{
Changes in Haematological Indices in Normal Pregnancy
}

\author{
Patrick Chukwuyenum Ichipi-Ifukor, ${ }^{1}$ Juliet Jacobs, ${ }^{2}$ \\ Rita Ngozi Ichipi-Ifukor, ${ }^{3}$ and Oberhiri Lawrence Ewrhe ${ }^{4,5}$ \\ ${ }^{1}$ Patychyky Research Consultancy, 16 College Road, Abraka, Nigeria \\ ${ }^{2}$ Department of Medical Physiology, Delta State University PMB 1, Abraka, Nigeria \\ ${ }^{3}$ Department of Biochemistry, University of Port Harcourt, PMB 5323, Port Harcourt, Nigeria \\ ${ }^{4}$ Department of Pharmacology Delta State University PMB 1, Abraka, Nigeria \\ ${ }^{5}$ Emma-Maria Laboratories and Consultancy, 45 Old Sapele Agbor Road C/O PMB 1, Abraka, Nigeria
}

Correspondence should be addressed to Patrick Chukwuyenum Ichipi-Ifukor; patychykyresearch@hotmail.com

Received 15 August 2013; Revised 21 October 2013; Accepted 4 November 2013

Academic Editor: Juan J. Loor

Copyright (C) 2013 Patrick Chukwuyenum Ichipi-Ifukor et al. This is an open access article distributed under the Creative Commons Attribution License, which permits unrestricted use, distribution, and reproduction in any medium, provided the original work is properly cited.

\begin{abstract}
Variation in some haematological indices during normal pregnancy was investigated. The test group comprised 200 pregnant women who presented themselves at the Capitol Hill Clinic Warri, Delta State, Nigeria, for antenatal care while the control group comprised 80 nonpregnant women randomly selected from the student population in Delta State University, Abraka. Data generated from the pretest questionnaire indicated that $55.8 \%$ of the research participants experienced an increase in appetite. The analysis of haematological indices was done using automated hematological analyzer. The result from the study showed that there was a significant decrease $(P<0.05)$ in the PCV of the test group $(32.58 \pm 4.01) \%$ when compared to the control $(37.07 \pm 3.19) \%$. Similarly, the result of the blood haemoglobin showed a significant difference $(P<0.05)$ between the test $(10.00 \pm 1.28) \mathrm{g} / \mathrm{dL}$ and the control group $(11.71 \pm 1.32) \mathrm{g} / \mathrm{dL}$ while granulocytes and platelets also showed significant decrease $(P<0.05)$ with lymphocytes increasing significantly; the total white blood cell count (WBC) showed no significant difference; there was an increased level compared to the control. The study concluded that pregnancy in women has the tendency to alter haematological indices.
\end{abstract}

\section{Introduction}

Normal pregnancy is characterized by profound changes in almost every organ and system to accommodate the demands of fetoplacental unit [1]. In normal pregnancy, the physiological change in haemoglobin concentration [HGB] and platelet count during pregnancy are well known phenomena [2]. It is also one of the physiological conditions capable of causing remarkable and dramatic changes in haematological variables. A pregnancy is influenced by many factors, some of which include culture, environment, socioeconomic status, and access to medical care. The haematological indices also have an impact on pregnancy and its outcome [2].

The haematological indices of an individual to a large extent reflect their general health [3]. Blood is a special type of connective tissue composed of formed elements in a fluid matrix. Many of the hematological indices are influenced by many factors like sex, seasonal variation, lactation, pregnancy health, and nutritional status [4]. It is also acknowledged that for comparisons between individuals and with reference data in a clinical diagnostic situation, it is necessary to consider the normal variations due to sex, age, and breed in order to increase diagnostic precision [5].

In normal pregnancy the haematological indices of an individual to a large extent reflect their general health [3] and many studies such as Osonuga et al. [6] and Shaw et al. [7] have identified the haematological indices of the pregnant woman as one of the factors affecting pregnancy. Anaemia (low haemoglobin) is a widely identified haematological abnormality [8] and it is also associated with adverse pregnancy outcome [9]. Anaemia in pregnant women is variously defined with two common parameters either as haemoglobin concentration less than $11.0 \mathrm{~g} / \mathrm{dL}$ or 5 th percentile of the distribution of haemoglobin concentration or haemotocrit 
in a healthy reference population [10]. This assessment is possible through a series of tests measuring different variables [11]. This study is of importance because systems monitored during antenatal care in an attempt to predict and/or improve pregnancy outcome are dependent on the quality and quantities of haematological indices.

\section{Objective of the Study}

The objective of the study is to evaluate the values of some major haematological indices among normal pregnant women. Thus this study focuses on the diagnostic evaluation of various conditions specifically the role of variation in white blood cell (WBC) count, haemoglobin, packed cell volume (PCV), granulocytes, lymphocyte, and platelet in the diagnosis of complications or challenges during pregnancy.

\section{Scope of the Study}

The present study was carried out on healthy women with normal pregnancy. Ranges of haematological indices and cases of anaemia among normal pregnant women were detected. Thus results of the study may be used as reference values in the assessment of the health status of normal pregnant women.

\section{Materials and Procedures}

The present study adopted the survey method. The Survey method is one which involves the assessment of public opinion using questionnaire and sampling methods. However, the present study employed the utilization of questionnaire and analysis of the haematological indices in pregnant women.

The materials used for the collection of the blood samples include

(1) $2 \mathrm{~mL}$ syringe

(2) EDTA container,

(3) universal bottles,

(4) toniquette,

(5) disposable hand gloves,

(6) micropipettes,

(7) automated haematological analyzer (produced by Shenzhen Mindray Bio-Medical Electronics Co. Ltd., China).

The sample of the present study comprised two groups of women. The first group which served as the test group comprised 200 pregnant women who presented themselves at the Capitol Hill Clinic Warri, Delta State, for antenatal care. The second group which served as control comprised 80 nonpregnant women randomly selected from the student population in Delta State University and Abraka town.

The sampling procedure employed for this study was the purposive random sampling. This was done because the researchers already had in mind the target group for the research. With the approval of the medical director of the
TABLE 1: Highest level of education attained.

\begin{tabular}{lcc}
\hline Status & Frequency & Percentage \\
\hline Primary & 27 & 22.5 \\
Secondary & 46 & 38.3 \\
Tertiary & 47 & 39.2 \\
\hline Total & 120 & 100 \\
\hline
\end{tabular}

Capitol Hill Clinic, the researchers interacted and educated the participants about the aims and objectives of the research work, and then questionnaires were distributed to those who out of their will decided to freely participate in the research process. The numbered and labeled questionnaire was, however, filled and returned immediately.

The research questionnaire for the study was purposely designed to suit the study. It comprised two sections of demographic/personal variables and information relating to their pregnancy/medical history. Participants were free to tick any of the responses that suit their condition.

Through the help of the nurses on duty, 200 blood samples were collected intravenously using standard procedures. The blood sample so collected was emptied and labeled corresponding to the patients' number in the questionnaire administered earlier and used for the analysis of haematological indices within 24 hours of collection. This procedure was done through the period of 4 weeks and at each time of collection, the answered questionnaire was immediately analyzed to note if the participants actually met the base line requirement for the research.

Following the analysis of the questionnaire presented by the research participants in the test group, 120 persons met the minimum requirement in the test group which disqualified smokers and participants who had had a series of pregnancy complication and heavy alcohol consumption. At the end of the sorting, blood samples was immediately taken to the laboratory section of the Capitol Hill Clinic Warri for haematological analysis using an automated haematological analyzer and the various results for the haematological indices were recorded.

Results obtained from the haematological screening and questionnaire were analyzed using descriptive statistics while paired $t$-test assuming unequal variance was used to determine the level of significant difference between the mean values at $P<0.05$ using the data tool pack of Microsoft Excel 2007.

\subsection{Presentation of Results. See Tables 1, 2, and 3.}

4.2. Observation on Current Medical Status. It was observed from the data gotten in the questionnaire that, of all the 120 participants whose blood samples were eventually accepted for haematological analysis, none of the women were then smoking or had a history of smoking. However, in relation to alcohol consumption, a few of them did agree to consume mild alcohol while about $46(38.3 \%)$ of the participants were having their first pregnancy. 
TABLE 2: Stage of pregnancy.

\begin{tabular}{lcc}
\hline Status & Number & Frequency (\%) \\
\hline First trimester & 40 & 33.4 \\
Second trimester & 55 & 45.8 \\
Third trimester & 25 & 20.8 \\
\hline Total & 120 & 100 \\
\hline
\end{tabular}

TABLE 3: Effect of pregnancy on appetite.

\begin{tabular}{lcc}
\hline Status & Number & Frequency (\%) \\
\hline No effect & 23 & 19.2 \\
Increased appetite & 67 & 55.8 \\
Decreased appetite & 30 & 25 \\
\hline Total & 120 & 100 \\
\hline
\end{tabular}

\section{Discussion}

The aim of the present study was to evaluate the haematological changes/variation that occurs during normal pregnancy. From the result presented in Table 4, it was discovered that there was a significant difference $(P<0.05)$ in the PCV of the test group $(32.58 \pm 4.01) \%$ when compared to the control $(37.07 \pm 3.19) \%$. This finding is in line with those of James et al. [5]. The decrease in PCV may be due to increase in plasma volume during pregnancy which causes haemodilution, and increased rate of infection especially malaria, hormonal changes, and conditions that promote fluid retention and iron deficiency.

The result of the blood haemoglobin showed a significant difference $(P<0.05)$ between the test $(10.00 \pm 1.28) \mathrm{g} / \mathrm{dL}$ and the control group $(11.71 \pm 1.32) \mathrm{g} / \mathrm{dL}$ while lymphocytes, granulocytes, and platelets also showed significant differences $(P<0.05)$, although the white blood cell count (WBC) showed no significant difference, there was an increased level compared to the control; thus the observation of a no significant difference in the total WBC count is in variance with the studies of Osonuga et al. [6], who observed a significant variation in the total WBC count of test groups compared to control. The observation of the various significant variations between the lymphocytes, granulocytes, and platelets has also been observed in previous studies by Wahed et al. [11].

White blood cells are responsible for body defense during pregnancy, WBC was reported to be elevated in this study, and the lymphocyte and granulocyte count were significantly higher in the test group compared to those of the controls. This agrees with previous work by Luppi [12], who asserted that a total lymphocyte count rising in early pregnancy will remain elevated through pregnancy. This may be as a result of the body building the immunity of the fetus and it is achieved by a state of selective immune tolerance, immunosuppression, and immunomodulation in the presence of a strong antimicrobial immunity. There is also downregulation of potentially dangerous T-cell-mediated immune responses, while activating certain components of the innate immune system, such as neutrophils. This unique dysregulation between different components of the immune system plays a central role in the maternal adaptation to pregnancy.
TABLE 4: Haematological indices.

\begin{tabular}{lccc}
\hline Parameter & Control & $\begin{array}{c}\text { Pregnant } \\
\text { women }\end{array}$ & $\begin{array}{c}\text { Reference } \\
\text { range }\end{array}$ \\
\hline PCV (\%) & $37.07 \pm 3.19$ & $32.58 \pm 4.01^{* *}$ & $34.9-43.7$ \\
$\mathrm{Hb}(\mathrm{g} / \mathrm{dL})$ & $11.71 \pm 1.32$ & $10.00 \pm 1.28^{* *}$ & $11.9-14.9$ \\
$\begin{array}{l}\text { Total WBC } \\
\text { (thousand) }\end{array}$ & $7633.33 \pm$ & $8394.74 \pm 7554.3$ & $4000-10,600$ \\
Lymphocytes (\%) & $23.4 \pm 6.9$ & $29.10 \pm 8.2^{* *}$ & $15.7-46.3$ \\
Granulocyte & $64.78 \pm 11.45$ & $59.91 \pm 7.71^{* *}$ & $45-74$ \\
(\% WBC) & $224.863 \pm$ & $202.177 \pm$ & $150-450$ \\
Platelet (thousand) & 75.21 & $48.75^{* *}$ & \\
\hline
\end{tabular}

All results are presented as mean $\pm \mathrm{SD}$ values. Results followed by ${ }^{* *}$ were significant at $P<0.05$.

It was also observed from the questionnaire analyzed that there was increased appetite in $67(55.8 \%)$ of the test participants. This observation may not be farfetched from the fact that adequate nutrition has been increasingly emphasized during pregnancy. A balanced, nutritious diet is an important aspect of a healthy pregnancy. Eating a healthy diet (balancing carbohydrates, fat, and proteins) and eating a variety of fruits and vegetables usually ensure good nutrition. Adequate periconceptional folic acid (also called foliate or vitamin $\mathrm{B}_{9}$ ) intake has been shown to decrease the risk of fetal neural tube defects such as spina bifida, a serious birth defect; thus when there is proper dieting, proper and adequate development of the child's cognitivity is achieved.

\section{Conclusion}

It can be concluded that pregnancy in women alters haematological indices such as PCV, haemoglobin, lymphocyte, and platelet counts and that during normal pregnancy, there is an increased level of appetite.

\section{General Comments}

(1) The quality of an haematological parameter as used in this study refers to the stability of the sum of all the haematological parameters while the quantity of haematological parameter refers to the stability of an individual haematological parameter.

(2) It is important to note here that, as part of the selection criteria, all participants in the study were screened for malaria. Thus they were all confirmed to be free from malaria at the time of the study.

(3) We acknowledge the importance of the haemoglobin genotypes to this study; our study however did not put into consideration this factor.

(4) The Source of the haematological reference range used for this study is the automated haematological analyzer reference range as produced by Shenzhen Mindray Bio-Medical Electronics Co. Ltd., China, the manufacturers of the haematological analyzer used for our study. 


\section{References}

[1] K. A. Harrison, "Blood volume changes in normal pregnant Nigerian women," The Journal of obstetrics and gynaecology of the British Commonwealth, vol. 73, no. 5, pp. 717-723, 1966.

[2] R. Yip, "Significance of an abnormally low or high hemoglobin concentration during pregnancy: special consideration of iron nutrition," The American Journal of Clinical Nutrition, vol. 72, no. 1, pp. 272-279, 2000.

[3] WHO, "Prevention and treatment of malaria during pregnancy," 2004, http://pdf.usaid.gov/pdf_docs/Pnada621.pdf.

[4] G. F. Smith, "An investigation into some of the effects of the state of nutrition of the mother during pregnancy and labour on the condition of the child at birth and for first few days of life," Nutrition, vol. 9, no. 4, pp. 388-392, 1993.

[5] T. R. James, H. L. Reid, and A. M. Mullings, "Are published standards for haematological indices in pregnancy applicable across populations: an evaluation in healthy pregnant Jamaican women," BMC Pregnancy and Childbirth, vol. 8, article 8, 2008.

[6] I. O. Osonuga, O. A. Osonuga, A. A. Onadeko, A. Osonuga, and A. A. Osonuga, "Hematological profile of pregnant women in southwest of Nigeria," Asian Pacific Journal of Tropical Disease, vol. 1, no. 3, pp. 232-234, 2011.

[7] J. L. V. Shaw, S. K. Dey, H. O. D. Critchley, and A. W. Horne, "Current knowledge of the aetiology of human tubal ectopic pregnancy," Human Reproduction Update, vol. 16, no. 4, Article ID dmp057, pp. 432-444, 2010.

[8] Centre for Disease Control And Prevention CDC, "Use of supplements containing folic acid among women child beareu age. United states," 2005.

[9] S. M. Garn, M. T. Keating, and F. Falkner, "Hematological status and pregnancy outcomes," The American Journal of Clinical Nutrition, vol. 34, no. 1, pp. 115-117, 1981.

[10] T. S. Imam and A. Yahaya, "Packed cell volume of pregnant women attending Dawakin Kudu General Hospital, Kano State, Nigeria," Int Jor P App Scs, vol. 2, no. 2, pp. 46-50, 2008.

[11] F. Wahed, S. Latif, M. Uddin, and M. Mahmud, "Fact of low hemoglobin and packed cell volume in pregnant women are at a stand still," Mymensingh Medical Journal, vol. 17, no. 1, pp. 4-7, 2008.

[12] P. Luppi, "How immune mechanisms are affected by pregnancy," Vaccine, vol. 21, no. 24, pp. 3352-3357, 2003. 

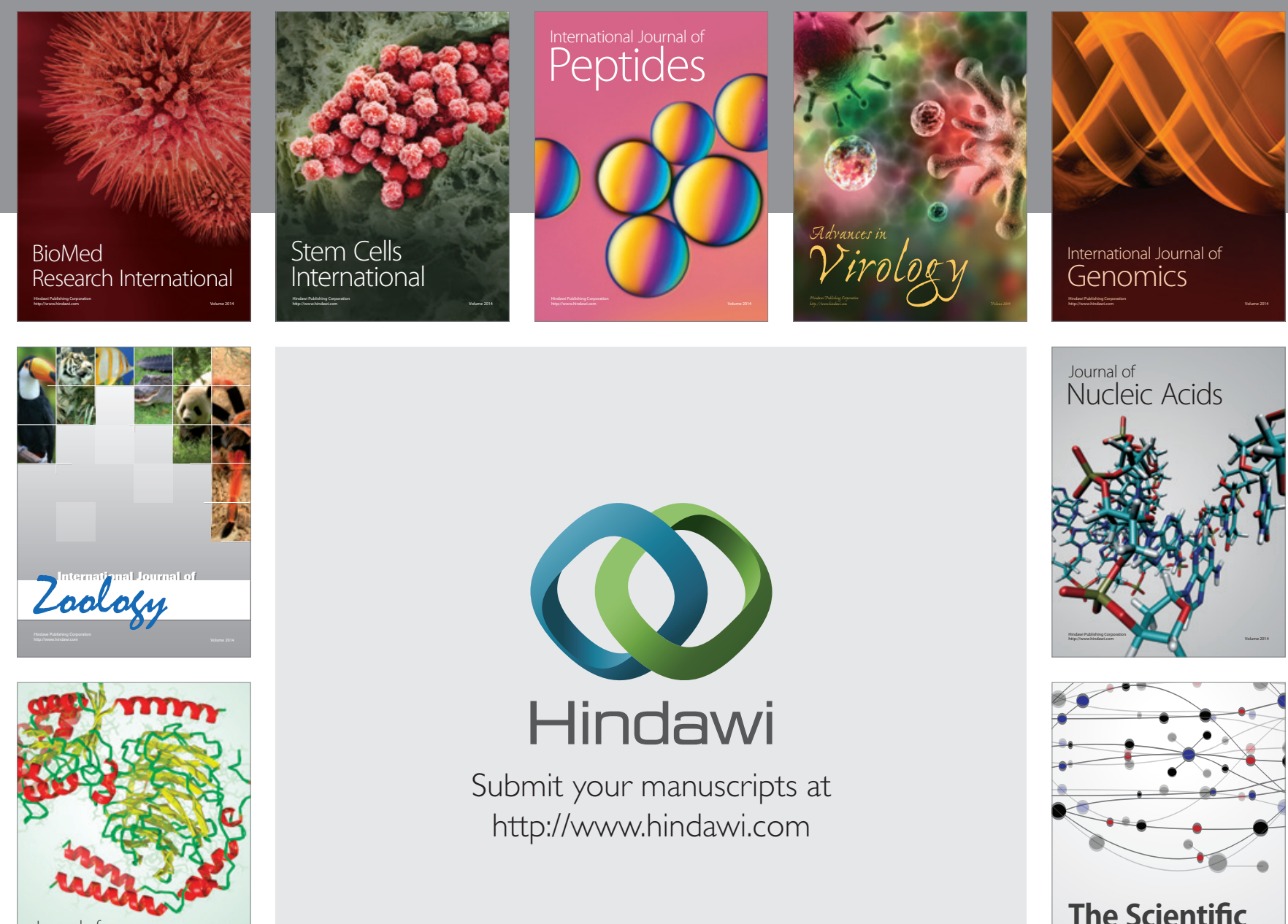

Submit your manuscripts at

http://www.hindawi.com

Journal of
Signal Transduction
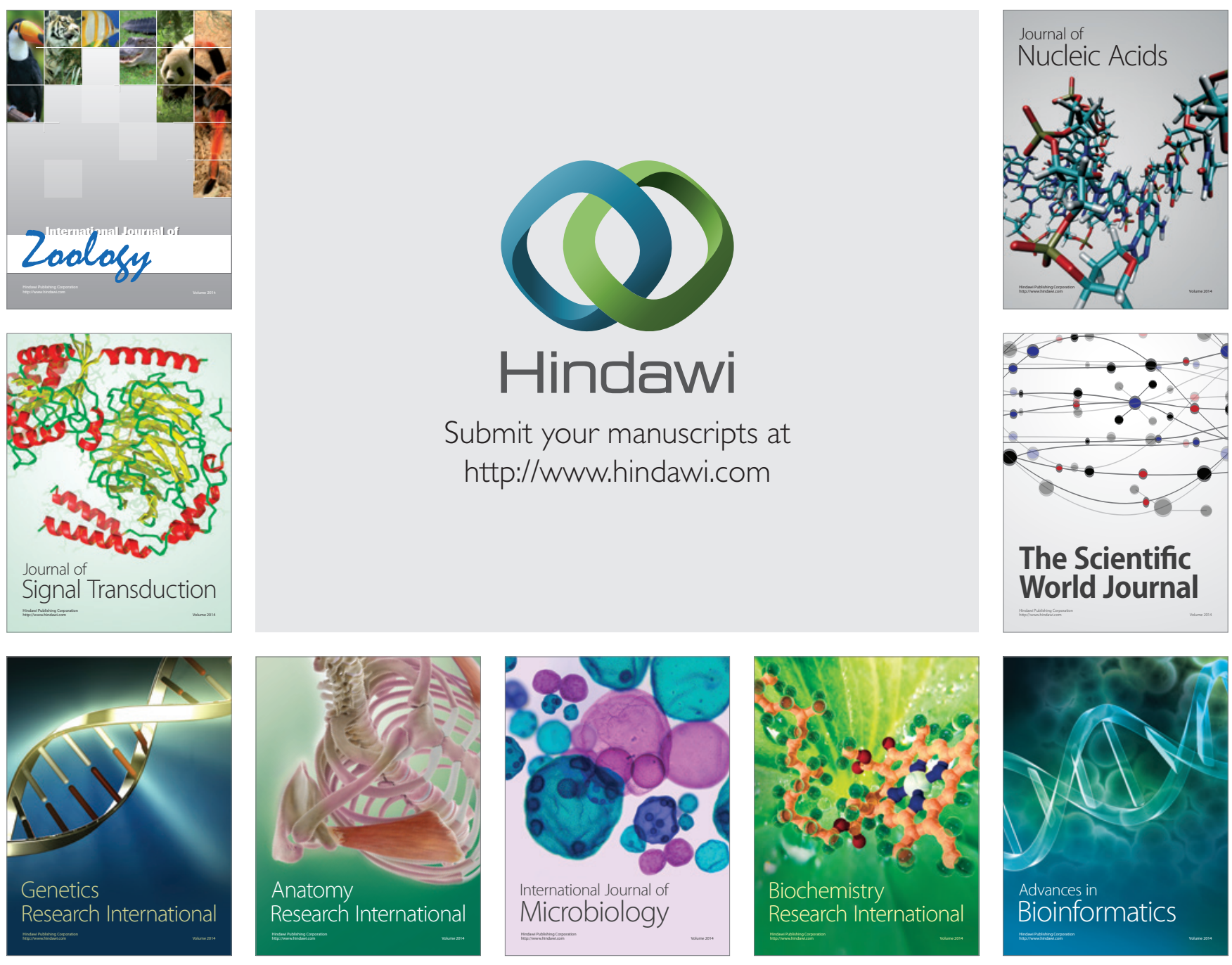

The Scientific World Journal
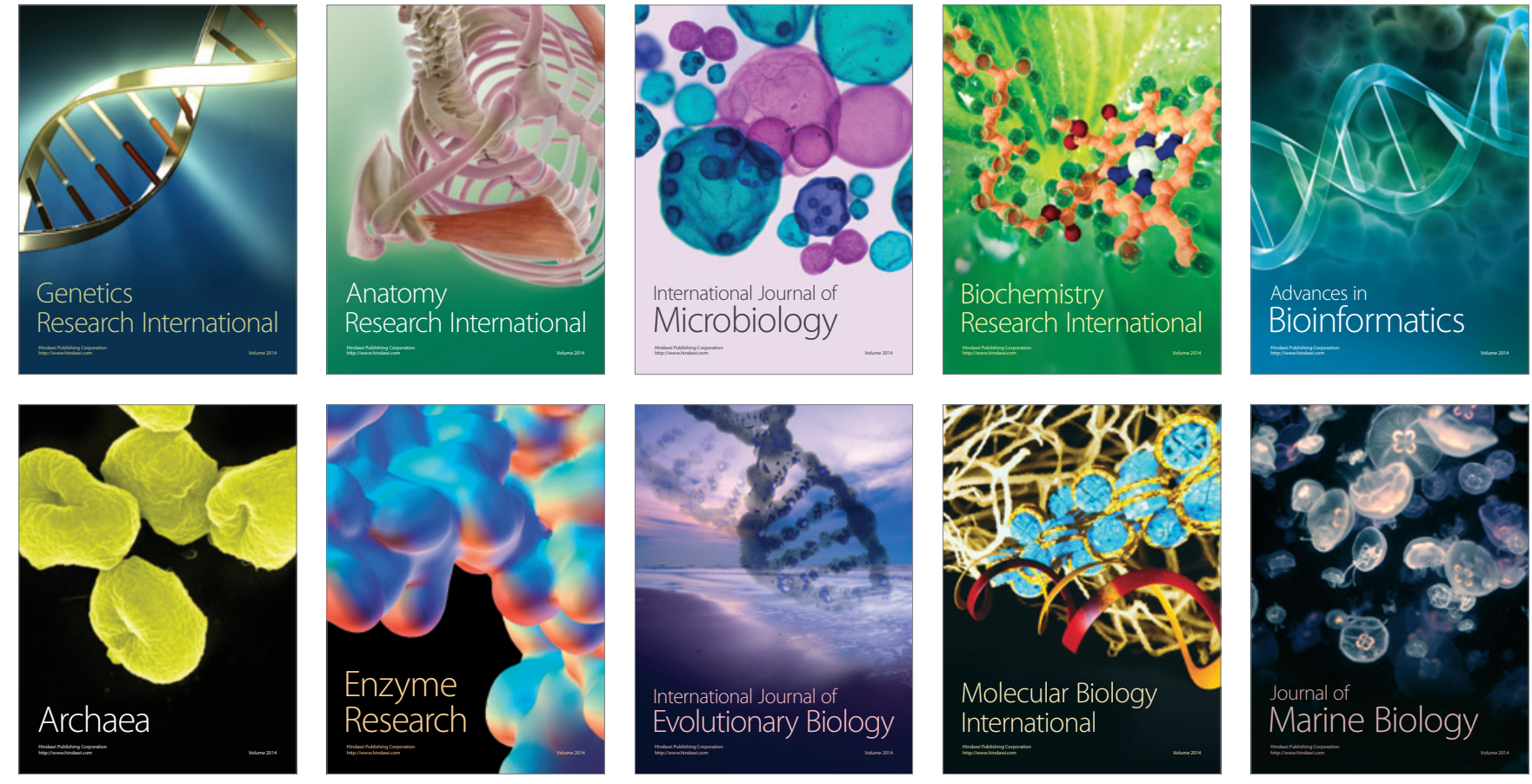